\title{
Efeito da concentração de ácido 3-indol-acético na ativação e crescimento in vitro de folículos pré-antrais ovinos
}

[Effect of indol acetic acid concentration in the activation and growth of ovine preantral follicles]

\author{
E.R. Andrade ${ }^{1 *}$, M.M. Seneda ${ }^{2}$, A.A. Alfieri ${ }^{2}$, J.A. Oliveira ${ }^{3}$, J.R. Figueiredo ${ }^{4}$, R. Toniolli ${ }^{4}$ \\ ${ }^{1}$ Doutoranda em Ciências Veterinárias \\ Faculdade de Agronomia e Veterinária - Universidade Estadual do Ceará - Fortaleza, CE \\ ${ }^{2} \mathrm{DCV}$ - CCA - UEL - Londrina, PR \\ ${ }^{3}$ FMVZ - UNESP - Jaboticabal, SP \\ ${ }^{4}$ FAVET - UECE - Fortaleza, CE
}

\begin{abstract}
RESUMO
Avaliou-se o desenvolvimento de folículos pré-antrais ovinos após o cultivo in vitro do córtex ovariano em várias concentrações de ácido 3-indol acético (IAA). O córtex ovariano foi dividido em fragmentos de aproximadamente $3 \times 3 \mathrm{~mm}$. Um fragmento foi imediatamente fixado em Bouin (controle - dia 0 ) e os demais destinados ao cultivo por dois ou seis dias em meio essencial mínimo (MEM+) acrescido de 10, 40, 100, 500 ou $1000 \mathrm{ng} / \mathrm{ml}$ de IAA. Após o cultivo in vitro, não houve variação entre folículos dos tratamentos e folículos-controle, exceto nos suplementados com 40ng/ml de IAA. Nestes observaram-se redução de folículos primordiais e aumento de folículos em desenvolvimento $(\mathrm{P}<0,05)$. Em relação aos folículos do grupo-controle, houve redução de pré-antrais normais no cultivo de seis dias $(\mathrm{P}<0,05)$. Após dois dias de cultivo, a redução foi observada somente nos folículos suplementados com $500 \mathrm{ou} 1000 \mathrm{ng} / \mathrm{ml}$ de IAA. Folículos pré-antrais ovinos podem ser ativados in vitro com sucesso após o cultivo em MEM+ suplementado com 40ng/ml de IAA.
\end{abstract}

Palavras-chave: ovino, folículo pré-antral, cultivo in vitro, ácido 3-indol acético

\begin{abstract}
The development of ovine preantral follicles after in vitro culture of ovarian cortex in various concentrations of indol acetic acid (IAA) was evaluated. The ovarian cortex was divided into fragments of approximately $3 \times 3 \mathrm{~mm}$. One fragment was immediately fixed in Bouin (control-day 0) whereas the other fragments were cultured for two or six days in minimum essential medium (MEM) supplemented (MEM+) with 10,40,100, 500 or 1000ng/ml of IAA. After six days of in vitro culture the percentage of primordial and developing follicles remained unaltered when compared to control follicles, except for MEM+ added of $40 \mathrm{ng} / \mathrm{ml}$ of IAA that presented reduction of primordial follicles and increase of developing follicles $(P<0.05)$. The culture of ovarian cortex for six days, in all tested media, reduced the percentages of healthy follicles when compared to control follicles $(P<0.05)$. After two days of culture this reduction was only observed in the follicles treated with 500 or $1000 \mathrm{ng} / \mathrm{ml}$ of IAA. Ovine primordial follicles may be successfully activated in vitro after culturing in MEM+ containing 40ng/ml of IAA.
\end{abstract}

Keywords: ovine, preantral follicle, in vitro culture, indol acetic acid

Recebido para publicação em 19 de janeiro de 2004

Recebido para publicação, após modificações, em 28 de julho de 2004

*Endereço para correspondência (corresponding address)

Rua Paranaguá, 450, apto. 102, Centro

86020-030 - Londrina, PR

E-mail: evelyn_andrade@yahoo.com 


\section{INTRODUÇÃO}

Ao nascimento, as fêmeas de mamíferos apresentam ovários com milhares de folículos primordiais (Hirshfield, 1991). No entanto, apenas alguns deles se desenvolvem até o estádio de folículo pré-ovulatório, pois a maioria torna-se atrésica após iniciar o crescimento in vivo (Eppig e O’Brien, 1996). Os folículos primordiais constituem importante fonte de oócitos que podem ser utilizados em estudos in vitro. Nesse sentido, a biotécnica de manipulação de oócitos inclusos em folículos pré-antrais objetiva o desenvolvimento in vitro de folículos primordiais até o oócito tornar-se apto à fecundação (Figueiredo et al., 1999). A ativação é a primeira e essencial etapa para o crescimento dos folículos primordiais (Fortune et al., 2000). Apesar de os fatores responsáveis pela ativação não se encontrarem totalmente esclarecidos, destaca-se o nascimento de um camundongo a partir da manipulação de oócitos em folículos pré-antrais (Eppig e O’Brien, 1996).

O crescimento in vitro de folículos primordiais depende de métodos de cultivo capazes de ativar o folículo primordial, além de promover sua manutenção e crescimento até o estádio antral. O meio essencial mínimo (MEM) tem sido usado com sucesso no cultivo in vitro de córtex ovariano bovino (Braw-Tal e Yossefi, 1997) e de folículos pré-antrais isolados (Figueiredo et al., 1994). A adição do ácido 3indol acético (IAA) viabilizou a conservação de sêmen caprino (Nunes e Combarnous, 1995), suíno (Toniolli et al., 1996) e humano (Nunes, 1998). Entretanto, o papel do MEM suplementado com IAA no desenvolvimento folicular permanece desconhecido. $\mathrm{O}$ objetivo deste estudo foi estabelecer condições de cultivo in vitro que permitam e mantenham o crescimento e a sobrevivência de folículos préantrais ovinos com diferentes concentrações de IAA.

\section{MATERIAL E MÉTODOS}

Ovelhas adultas $(n=4)$, sem raça definida, foram abatidas para obtenção dos ovários. As oito gônadas foram submersas em álcool a 70,0 \% por 10 segundos e lavadas duas vezes em solução salina a $0,9 \%$. Os ovários, depositados em solução salina a $0,9 \%$ suplementada com penicilina $(200 \mathrm{UI} / \mathrm{ml})$ e estreptomicina $(200 \mathrm{mg} / \mathrm{ml})$ a $39^{\circ} \mathrm{C}$, foram imediatamente transportados para o laboratório em tempo inferior a uma hora.

No laboratório, após a retirada dos ligamentos e do tecido circundante dos ovários seccionou-se cada gônada, longitudinalmente, para retirada da medula, grandes folículos antrais e corpos lúteos. $\mathrm{O}$ córtex foi dividido em fragmentos de aproximadamente $3 \times 3 \times 1 \mathrm{~mm}$. Um fragmento, escolhido aleatoriamente, foi fixado em Bouin para análise histológica - tratamento-controle (TC) - dia 0. Os outros fragmentos foram cultivados individualmente em placas de cultivo de 24 poços, cada um contendo $1 \mathrm{ml}$ dos seguintes meios: MEM suplementado com penicilina $\quad(200 \mathrm{UI} / \mathrm{ml}), \quad$ estreptomicina $(200 \mathrm{mg} / \mathrm{ml})$, albumina sérica bovina $(1,25 \mathrm{mg} / \mathrm{ml})$, insulina $(6,25 \mu \mathrm{g} / \mathrm{ml})$, transferrina $(6,25 \mu \mathrm{g} / \mathrm{ml})$ e selênio $(6,25 \mathrm{ng} / \mathrm{ml}(\mathrm{MEM}+; \mathrm{T} 1)$, MEM+ suplementado com $10 \mathrm{ng} / \mathrm{ml}$ de IAA (T2), MEM+ suplementado com 40ng/ml de IAA (T3), MEM+ suplementado com 100ng/ml de IAA (T4), MEM+ suplementado com 500ng/ml de IAA (T5) e MEM+ suplementado com $1000 \mathrm{ng} / \mathrm{ml}$ de IAA (T6), como apresentado na Fig. 1 . O cultivo in vitro foi realizado a $39^{\circ} \mathrm{C}$ em atmosfera com $5 \% \mathrm{CO}_{2}$, durante dois ou seis dias, conforme o tratamento. Foram realizadas quatro réplicas de cada tratamento.

No TC e nos dias dois ou seis, os fragmentos de córtex ovariano de cada tratamento foram destinados ao processamento histológico clássico. $\mathrm{O}$ procedimento inicial consistiu na fixação em Bouin por 24h, com posterior desidratação em etanol, diafanização em xilol e imersão em parafina. Cada fragmento foi cortado de forma seriada a cada $5 \mu \mathrm{m}$. As secções resultantes foram montadas em lâminas e coradas pelo método hematoxilina-eosina.

Os folículos foram classificados de acordo com o estádio de desenvolvimento. Como primordiais, consideraram-se aqueles com uma camada de células da granulosa de formato pavimentoso envolvendo o oócito. Três categorias foram consideradas como folículos em desenvolvimento. Os folículos primários iniciais (primeira categoria) apresentavam uma camada de células da granulosa de formato pavimentoso-cúbico envolvendo o oócito. Nos 
folículos primários (segunda categoria), observou-se uma camada de células da granulosa de formato cúbico envolvendo o oócito. A terceira categoria consistiu de folículos secundários, cujos oócitos estavam envolvidos por duas ou mais camadas de células da granulosa de formato cúbico (Fortune et al.,
1998). A morfologia folicular foi avaliada de acordo com a integridade da membrana basal, a densidade celular, a ocorrência de corpos picnóticos e a integridade do oócito. Cada folículo foi classificado como morfologicamente normal ou degenerado. Foram avaliados 120 folículos por tratamento, sendo 30 por réplica.

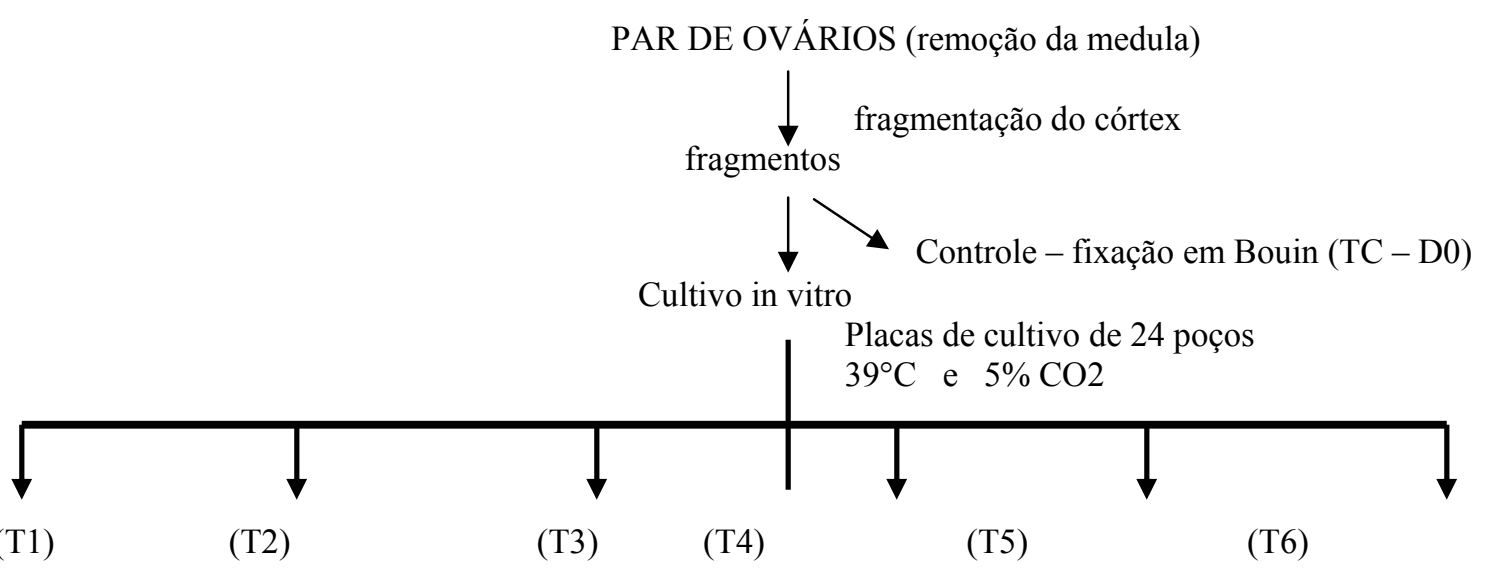

Figura 1. Protocolo experimental para o cultivo in vitro de folículos primordiais ovinos na presença ou ausência de IAA.

A eficiência para indução da ativação foi considerada pelo aumento do percentual de folículos em desenvolvimento e redução do percentual de folículos primordiais. Esta análise foi realizada a partir da comparação dos folículos do grupo-controle e folículos dos tratamentos dos dias 2 e 6 de cultivo. A viabilidade dos folículos foi considerada a partir do percentual de folículos pré-antrais morfologicamente normais. A comparação foi realizada entre os folículos do grupo-controle e os folículos dos tratamentos dos dias 2 e 6 de cultivo. A eficiência para indução da ativação e a viabilidade dos folículos foram comparadas pelo teste Tukey $(\mathrm{P}<0,05)$.

\section{RESULTADOS}

Em relação à ativação folicular, nos folículos fixados logo após a obtenção dos ovários (TC), verificaram-se $92,6 \%$ de folículos primordiais e $7,4 \%$ de folículos em desenvolvimento. Após dois dias de cultivo, essa proporção permaneceu inalterada, exceto nos folículos do T3. Neste tratamento, observou-se redução do percentual de folículos primordiais para $64,2 \%$ e acréscimo de folículos em desenvolvimento para 35,8\%, $(\mathrm{P}<0,05)$. Após seis dias de cultivo, os melhores resultados de ativação foram obtidos nos folículos submetidos ao T3 e T4, respectivamente, $48,4 \%$ e $34,1 \%$ de folículos em desenvolvimento $(\mathrm{P}<0,05)$. Os tratamentos mais ineficazes para induzir a ativação após seis dias de cultivo foram o T1 e T5, respectivamente, com $12,5 \%$ e $10,8 \%$ de folículos em desenvolvimento $(\mathrm{P}<0,05)$. A apresentação detalhada desses dados é mostrada na Tab. 1.

Os resultados da viabilidade folicular são apresentados na Tab. 2. Foram considerados os percentuais dos folículos pré-antrais normais no fragmento controle (TC) e após o cultivo por dois e seis dias nos tratados. No córtex ovariano cultivado por seis dias, em todos os meios testados, verificou-se redução da porcentagem de folículos morfologicamente normais em relação aos folículos do $\mathrm{TC}(\mathrm{P}<0,05)$. Nos folículos cultivados por dois dias, os resultados mais favoráveis foram observados em T1, T3 e T4. A proporção de folículos morfologicamente normais nestes tratamentos foi similar à do tratamento controle $(\mathrm{P}>0,05)$. 
Efeito da concentração de ácido 3-indol-acético...

Tabela 1. Porcentagem de folículos primordiais e em desenvolvimento em tecido não-cultivado (TC) e no tecido após cultivo por dois e seis dias nos diferentes tratamentos

\begin{tabular}{lcccc}
\hline Variável & \multicolumn{2}{c}{ Folículos primordiais (\%) } & \multicolumn{2}{c}{ Folículos em desenvolvimento (\%) } \\
\hline TC & \multicolumn{2}{c}{92,6} & \multicolumn{3}{c}{7,4} \\
\hline Cultivado & Dia 2 & Dia 6 & Dia 2 & Dia 6 \\
\hline T1 & $88,4 \mathrm{aA}$ & $87,5 \mathrm{aA}$ & $11,6 \mathrm{aA}$ & $12,5 \mathrm{aA}$ \\
T2 & $90,9 \mathrm{aA}$ & $78,6 \mathrm{aAB}$ & $9,1 \mathrm{aA}$ & $21,4 \mathrm{aA}, \mathrm{B}$ \\
T3 & $64,2 * \mathrm{aB}$ & $51,6 * \mathrm{bB}$ & $35,8 * \mathrm{aB}$ & $48,4 * \mathrm{aC}$ \\
T4 & $88,3 \mathrm{aA}$ & $65,9 * \mathrm{bB}$ & $11,7 \mathrm{aA}$ & $34,1 * \mathrm{bB}, \mathrm{C}$ \\
T5 & $85 \mathrm{aA}$ & $89,2 \mathrm{aA}$ & $15 \mathrm{aA}$ & $10,8 \mathrm{aA}$ \\
T6 & $91,8 \mathrm{aA}$ & $75,8 \mathrm{aA}, \mathrm{B}$ & $8,2 \mathrm{aA}$ & $24,2 \mathrm{aA}, \mathrm{B}$ \\
\hline
\end{tabular}

* Difere significativamente do tecido não cultivado

Valores seguidos por letras distintas minúsculas na linha e maiúsculas na coluna diferem entre si $(\mathrm{P}<0,05)$.

$\mathrm{T} 1=\mathrm{MEM}+; \mathrm{T} 2=\mathrm{MEM}+\mathrm{IAA}(10 \mathrm{ng} / \mathrm{ml}) ; \mathrm{T} 3=\mathrm{MEM}+\mathrm{IAA}(40 \mathrm{ng} / \mathrm{ml}) ; \mathrm{T} 4=\mathrm{MEM}+\mathrm{IAA}(100 \mathrm{ng} / \mathrm{ml}) ; \mathrm{T} 5=\mathrm{MEM}+\mathrm{IAA}(500 \mathrm{ng} / \mathrm{ml})$; MEM+IAA $(1000 \mathrm{ng} / \mathrm{ml})$.

Tabela 2. Viabilidade folicular em tecido nãocultivado (TC) e no tecido após cultivo por dois e seis dias nos diferentes tratamentos

\begin{tabular}{lcc}
\hline Variável & \multicolumn{3}{c}{ Viabilidade folicular } \\
\hline TC & \multicolumn{3}{c}{96,6} \\
\hline Cultivado & Dia 2 & Dia 6 \\
\hline T1 & $83,3 \mathrm{a}, \mathrm{A}$ & $66,6^{*} \mathrm{a}, \mathrm{A}$ \\
T2 & $80,8 \mathrm{a}, \mathrm{AB}$ & $65,8^{*} \mathrm{a}, \mathrm{A}$ \\
T3 & $83,5 \mathrm{a}, \mathrm{A}$ & $75,8 * \mathrm{a}, \mathrm{A}$ \\
T4 & $88,3 \mathrm{a}, \mathrm{A}$ & $68,3 * \mathrm{~b}, \mathrm{~A}$ \\
T5 & $64,1 * \mathrm{a}, \mathrm{B}$ & $48,3 * \mathrm{a}, \mathrm{B}$ \\
T6 & $64,6 * \mathrm{a}, \mathrm{B}$ & $38,3 * \mathrm{~b}, \mathrm{~B}$ \\
\hline
\end{tabular}

* Difere significativamente do tecido não cultivado

Valores seguidos por letras distintas minúsculas na linha e maiúsculas na coluna diferem entre si $(\mathrm{P}<0,05)$

$\mathrm{T} 1=\mathrm{MEM}+; \mathrm{T} 2=\mathrm{MEM}+\mathrm{IAA}(10 \mathrm{ng} / \mathrm{ml}) ; \mathrm{T} 3=\mathrm{MEM}+\mathrm{IAA}$ $(40 \mathrm{ng} / \mathrm{ml}) ; \mathrm{T} 4=\mathrm{MEM}+\mathrm{IAA}(100 \mathrm{ng} / \mathrm{ml}) ; \mathrm{T} 5=\mathrm{MEM}+\mathrm{IAA}$ $(500 \mathrm{ng} / \mathrm{ml}) ;$ MEM+IAA $(1000 \mathrm{ng} / \mathrm{ml})$.

\section{DISCUSSÃO}

Os resultados permitem considerar a relação dose dependente do IAA no crescimento de folículos pré-antrais ovinos inclusos no tecido ovariano. A partir de dois dias de cultivo, constataram-se a ativação de folículos primordiais e $\mathrm{o}$ seu subseqüente desenvolvimento. Resultados similares foram descritos para folículos primordiais bovinos (Braw-Tal e Yossefi, 1997) e babuínos (Fortune et al., 1998).

O mecanismo responsável pela ativação desses folículos não foi completamente esclarecido. Em condições naturais, o processo de ativação ocorre regulamente ao longo da vida reprodutiva da fêmea (Nilsson et al., 2002). Os processos de cultivo in vitro poderiam acelerar a ativação dos folículos primordiais, pela maior disponibilidade de nutrientes e oxigênio (Wandji et al.; 1997; Wezel e Rodgers, 1996). Outra hipótese seria a presença de um inibidor da ativação folicular de origem medular. Esta inibição cessaria com a separação do córtex e da medula, primeira etapa do procedimento in vitro (Wandji et al., 1996). Essa idéia é sustentada pelos resultados de Eppig e O’Brien (1996), que observaram reduzido percentual de ativação de folículos primordiais quando ovários inteiros foram cultivados in vitro. No entanto, a ativação não foi inibida quando fragmentos de córtex ovariano bovino foram cultivados na presença de tecido medular (Derrar et al., 2000).

As auxinas constituem um grupo de hormônios vegetais, sendo o IAA um dos mais importantes (Toniolli et al., 1996). Os mecanismos de ação de auxinas em plantas foram explicados por Barbier-Brygoo (1995). As auxinas ligam-se a uma proteína solúvel, e o complexo formado associa-se a um receptor de membrana (Toniolli et al., 1996). As ações resultantes compreendem aumento da plasticidade da parede celular, alteração na permeabilidade celular, além de modificações nos padrões respiratórios e no metabolismo de ácidos nucléicos (Galston e Purves, 1960). A ação das auxinas em células animais ainda é pouco conhecida. Nunes e Combarnous (1995) relataram a ação benéfica do IAA em espermatozóides caprinos, facilitando sua conservação, além do aumento da motilidade e conseqüente incremento da fertilidade. Resultados promissores também foram obtidos com sêmen suíno, conservado satisfatoriamente na presença de IAA (Toniolli et al., 1996).

Os resultados deste trabalho evidenciam a relação dose resposta do IAA no cultivo in vitro dos folículos pré-antrais ovinos. Observaram-se ativação e crescimento folicular após dois e seis 
dias de cultivo in vitro apenas com $40 \mathrm{ng} / \mathrm{ml}$ de IAA. Esta concentração é a mesma da auxina ativa encontrada na água-de-coco (Dua e Chandra, 1993) e esta é a provável razão do seu sucesso nos protocolos de conservação de folículos pré-antrais caprinos (Silva et al., 2000) e ovinos (Andrade et al., 2002).

Constatou-se redução da porcentagem de folículos normais quando o córtex ovariano foi cultivado por apenas dois dias em meio contendo IAA nas concentrações de 500ng/ml e $1000 \mathrm{ng} / \mathrm{ml}$. Resultados semelhantes foram descritos por Ferreira et al. (2001). Esses autores observaram decréscimo na porcentagem de folículos pré-antrais caprinos morfologicamente normais conservados em TCM 199 com $100 \mathrm{ng} / \mathrm{ml}$ por até $24 \mathrm{~h}$.

Os efeitos deletérios do IAA são pouco conhecidos. Formas reativas de oxigênio podem ser formadas após sua peroxidação, gerando produtos citóxicos (Pires de Melo et al., 1992; Folkes e Wardman, 2001). Pires de Melo et al. (1997) relataram o efeito moderadamente citotóxico do IAA em neutrófilos. A morte celular foi relacionada à atividade de peroxidases endógenas, causando alterações ultra-estruturais e produção elevada de radicais superóxido e peróxido de hidrogênio. Células HL60 humanas perderam aproximadamente $25,0 \%$ da viabilidade, $72 \mathrm{~h}$ após o cultivo por $1 \mathrm{~h}$ com IAA (Folkes et al., 1998). O IAA em altas concentrações pode ligar-se à glutationa Stransferase (GST), reduzindo sua atividade em substratos nos tecidos vegetais (Bilang e Sturm, 1995). Ressalta-se que a GST tem importante atuação na proteção contra o dano oxidativo em tecidos vegetais e animais (Irzyk e Fuerst, 1993).

Conclui-se que folículos pré-antrais ovinos podem ser ativados in vitro com sucesso após o cultivo em MEM+ suplementado com $40 \mathrm{ng} / \mathrm{ml}$ de IAA e que altas concentrações desse ácido podem ser deletérias para esses folículos.

\section{REFERÊNCIAS BIBLIOGRÁFICAS}

ANDRADE, E.R.; AMORIM, C.A.; MATOS, M.H.T. et al. Evaluation of saline and coconut water solutions in the preservation of sheep preantral follicles in situ. Small Rum. Res., v.43, p.235-243, 2002.

BARBIER-BRYGOO, H. Tracking auxin receptors using functional approaches. Crit. Rev. Plant., v.14, p.1-25, 1995.

BILANG, J.; STURM, A. Cloning and characterization of a glutathione S-transferase that can be photolabeled with 5-azido-indole-3acetic acid. Plant Physiol., v.109, p.253-260, 1995.

BRAW-TAL, R.; YOSSEFI, S. Studies in vivo and in vitro on the initiation of follicle growth in the bovine ovary. J. Reprod. Fertil., v.109, p.165-171, 1997.

DERRAR, N.; PRICE, C.A.; SIRARD, M.A. Effect of growth factors and co-culture with ovarian medulla on the activation of primordial follicles in explants of bovine ovarian cortex. Theriogenology, v.54, p.587-598, 2000.

DUA, L.S.; CHANDRA, M. The identification and isolation of plant growth regulating substances from the liquid endosperm of Cocus nucifera. Coconut Res. Dev., p.219-227, 1993.

EPPIG, J. J.; O'BRIEN, M. J. Developmental in vitro of mouse oocytes from primordial follicles. Biol. Reprod., v.54, p.197-207, 1996.

FERREIRA, M.A.L.; BRASIL, A.F.; SILVA, J.R.V. et al. Effects of storage time and temperature on atresia of goat ovarian preantral follicles held in M199 with or without indole-3acetic acid supplementation. Theriogenology, v.55, p.1607-1617, 2001.

FIGUEIREDO, J.R.; HULSHOF, S.C.J.; VAN DEN HURK, R. et al. Preservation of Oocyte and Granulosa Cell Morphology in Bovine Preantral Follicles Cultured in vitro. Theriogenology, v.41, p.1333-1346, 1994.

FIGUEIREDO, J.R.; SILVA, J.R.V.; RODRIGUES, A.P.R. Estado atual da biotécnica de manipulação de oócitos inclusos em folículos pré-antrais (MOIFOPA). Ciên. Anim., v.9, p.11$25,1999$.

FOLKES, L.K.; CANDEIAS, L.P.; WARDMAN, P. Toward targeted "oxidation therapy" of cancer: peroxidase-catalysed cytotoxicity of indole-3-acetic acids. Int. J. Radiat. Oncol. Biol. Phys., v.42, p.917-920, 1998. 
FOLKES, L.K.; WARDMAN, P. Oxidative activation of indole-3-acetic acids to cytotoxic species - a potential new role for plant auxins in cancer therapy. Biochem. Pharmac., v.61, p.129136, 2001.

FORTUNE, J.E.; CUSHMAN, R.A.; WAHL, C.M. et al. The primordial to primary follicle transition. Mol. Cel. Endocrinol., v.163, p.53-60, 2000 .

FORTUNE, J.E.; KITO, S.; WANDJI, S.A. et al. Activation of bovine and baboon primordial follicles in vitro. Theriogenology, v.49, p.441449, 1998

GALSTON, A.W.; PURVES, W.K. The mechanism of action of auxin. Ann. Rev. Plant Physiol., v.11, p.239-276, 1960.

HIRSHFIELD, A.N. Development of follicles in the mammalian ovary. Int. Rew. Cytol., v.124, p.43-101, 1991.

IRZYK, G.P.; FUERST, E.P. Purification and characterization of a glutathione S-transferase from benoxacor-treated maize (Zea mays). Plant Physiol., v.102, p.803-810, 1993.

NILSSON, E.E.; KEZELE, P.; SKINNER, M.K. Leukemia inhibitory factor (LIF) promotes the primordial to primary follicle transition in rat ovaries. Mol. Cell. Endocrinol., v.188, p.65-73, 2002.

NUNES, J.F. Utilização da água de coco como diluidor do sêmen de animais domésticos e do homem. Rev. Bras. Reprod. Anim., v.22, p.109112,1998

NUNES, J.F.; COMBARNOUS, Y. Utilização da água de coco e suas frações ativas como diluidor do sêmen dos mamíferos domésticos. In: SIMPÓSIO DE BIOTECNOLOGIA DA REPRODUÇÃO DE ANIMAIS DOMÉSTICOS, 1. Fortaleza, 1995. p.53-63.

PIRES DE MELO, M.; CURI, T.C.P.; CURI, R. et al. Peroxidase activity may play a role in the citotoxic effect of indole acetic acid. Photochem. Photobiol., v.65, p.338-341, 1997.

PIRES DE MELO, M.; ESCOBAR, J.A.; METODIEWA, D. et al. Horseradish peroxidasecatalysed oxidation of indole-3-acetic acid II: oxygen uptake and chemiexcitation. Arch. Biochem. Biophys., v.296, p.34-39, 1992.

SILVA, J.R.V.; LUCCI, C.M.; CARVALHO, F.C.A. et al. Effect of coconut water and BraunCollins solutions at different temperatures and incubation times on the morphology of goat preantral follicles preserved in situ. Theriogenology, v.54, p.809-822, 2000.

TONIOLLI, R.; BUSSIÈRE, J.; COUROT, M. et al. Effect of indole-3-acetic acid (plant auxin) on the preservation at $15^{\circ} \mathrm{C}$ of boar semen for artificial insemination. Reprod. Nutr. Dev., v.36, p.503-511, 1996.

WANDJI, S.A.; SRSEN, V.; NATHANIELSZ, P.W. et al. Initiation of growth of baboon primordial follicles in vitro. Human Reprod., v.12, p.1993-2001, 1997.

WANDJI, S.A.; SRSEN, V.; VOSS, A.K. et al. Initiation of growth of bovine primordial follicles. Biol. Reprod., v.55, p.942-948, 1996.

WEZEL, I.L.; RODGERS, R.J. Morphological characterization of bovine primordial follicles and their environment in vivo. Biol. Reprod., v.55, p.1003-1011, 1996. 